\title{
Salmo salar: morfología ultraestructural de la pared del corion en ovas normales y con problemas de eclosión ${ }^{\#}$
}

\author{
Salmo salar: ultrastructural morphology of chorion, from normal and \\ with hatching problems ova \\ R Jaramillo*, O Goicoechea, O Garrido, E Molinari \\ Instituto de Embriología, Facultad de Ciencias, Universidad Austral de Chile, Valdivia, Chile.
}

\begin{abstract}
SUMMARY
Either eyed alevins unable to digest the chorion or those digesting it partially, are both suffering the "hard chorion" phenomenon; in both cases alevins can not survive producing high mortality rates. During recent years, the salmon farming industry in Southern Chile has been facing massive mortality events caused by "hard chorion". Since "hard chorion" is a recently observed phenomenon there are no literature reporting its origin. The aim of this study was to find differences in the ultrastructure of chorion fibers from Salmo salar ova at different stages of development by using Scanning Electron Microscopy and image analysis technique. Early results here reported indicated no differences in thickness of chorion fibers for Salmo salar ova at different stages of development, however differences in spatial arrangement of fibers forming the inner layer of chorion seem to explain the "hard chorion" occurrence. No pores were observed in the inner layer of chorion of ova exhibiting "hard chorion" as opposed to normally developed ova which have pores and allow hatching of alevins. Since choriogenin is a protein formed by a number of sub-units, it is possible that failure in synthesis of one of these sub-units might be responsable for an anomalous arrangement of fibers of chorion causing the "hard chorion" phenomenon.
\end{abstract}

Palabras clave: Salmo salar, reproducción, ultraestructura, corion.

Key words: Salmo salar, reproduction, ultrastructure, chorion.

\section{INTRODUCCIÓN}

El desarrollo ontogenético en peces ocurre a través de una sucesión de estados que conducen al nacimiento del alevín durante el proceso denominado eclosión. El período de eclosión es la etapa en la cual el embrión emerge desde la envoltura que rodea al huevo (corion) durante el desarrollo, para constituirse en alevín con saco, el cual iniciará su fase de vida libre, primero utilizando el vitelo remanente en el saco vitelino como nutriente, para más tarde iniciar su alimentación externa.

Durante la ovogénesis, el hígado de la hembra de peces teleósteos sintetiza, entre otras, una proteína compleja llamada coriogenina (Darie y col 2005). Esta proteína está formada por tres subunidades, las cuales son transportadas a través del torrente sanguíneo hasta llegar al ovario en donde se ensamblan para constituir una cubierta protectora denominada envoltura vitelina o corion (Celius y Walther 1998).

Una vez ocurrida la fecundación, con la finalidad de evitar la poliespermia y de proteger al embrión durante su desarrollo, se produce el endurecimiento del corion,

Aceptado: 10.09.2008.

\# Proyecto DID UACH 200717.

* Casilla 567, Valdivia, Chile; jjaramil@uach.cl el cual permanecerá envolviendo al huevo fecundado hasta el momento en que ocurra la eclosión del alevín. Este endurecimiento parece producirse por la participación de $\mathrm{Ca}^{2+}$ en medio ácido, junto a mucopolisacáridos sometidos a reacciones de oxidorreducción, sumados a la formación de puentes disulfuros entre las proteínas del corion (Masuda y col 1992).

Bajo condiciones normales, el desarrollo de los embriones ocurre al amparo de la acción protectora del corion, pero alcanzado el estado de ova con ojo comienza la producción de enzimas de eclosión, las cuales inician el proceso de digestión de las paredes internas del corion. El adelgazamiento progresivo y considerable de esta envoltura permite que ocurra la ruptura del corion y la subsecuente salida de los alevines con saco desde su interior.

Los estudios relacionados con el corion, hasta ahora conocidos, hacen referencia al proceso de endurecimiento del corion postfecundación, a la caracterización de las enzimas participantes y los mecanismos involucrados en dicho proceso (Iuchi y col 1991, Masuda y col 1992, Iconomidou y col 2000, Darie y col 2005). Sin embargo, y a pesar de las evidencias químicas y espectroscópicas que muestran cambios estructurales en la conformación de las proteínas del corion luego del proceso de fecundación, no existen estudios que muestren las características ultraestructurales del corion previo a la fecundación y luego de ocurrido el endurecimiento. 
Por otra parte, y directamente relacionado con el proceso de eclosión, se ha podido observar que en algunas pisciculturas dedicadas a la producción de alevines de salmónidos en el sur de Chile han ocurrido fracasos reproductivos importantes debido a que un gran porcentaje de ovas con ojo de algunas cohortes no logran romper el corion. Un porcentaje menor de ovas logra romper el corion de manera parcial, por lo que una parte del cuerpo del embrión o parte de su saco vitelino eclosiona, quedando el resto del embrión o del saco atrapado al interior de la cavidad coriónica, lo que lleva a la muerte del alevín. Debido a que en apariencia el corion se transforma en una barrera difícil de romper o degradar este fenómeno ha sido denominado comúnmente como "corion duro".

Este problema ha sido reportado principalmente en ovas de Salmo salar y Oncorhynchus kisutch, pero parece ser un fenómeno generalizado entre los salmonídeos, ya que también se ha observado en otras especies cultivadas en el sur de Chile, tales como Salmo trutta y Oncorhynchus mykiss, desconociéndose hasta ahora la razón por la cual el corion es digerido de manera parcial por las enzimas de eclosión.

Como este fenómeno parece ser de reciente ocurrencia, hasta el momento no existen antecedentes que expliquen el origen del "corion duro". Sin embargo, y como resultado de la observación macroscópica de los cambios que ocurren con las ovas entre el momento de su obtención y la posterior fecundación, es posible pensar que la organización estructural de las fibras proteicas que componen el corion o su distribución se encuentren alteradas en aquellas ovas que no eclosionan o que eclosionan parcialmente.

Un primer paso para entender este fenómeno sería el conocer las características de la organización estructural del corion normal en ovas sin fecundar y del corion de ovas postfecundación, y luego conocer las características del corion en ovas parcialmente eclosionadas o definitivamente sin eclosionar.

\section{MATERIAL Y MÉTODOS}

\section{RECOLECCIÓN DE OVAS}

Para el estudio de la ultraestructura normal del corion de ovas sin fecundar y ovas recién fecundadas se obtuvieron ovas de Salmo salar desde una piscicultura de la Décima Región.

El corion de ovas eclosionadas y sin eclosionar se obtuvo a partir de cohortes de Salmo salar provenientes de la misma empresa y colectadas en el momento en que se presentó el fenómeno de "corion duro".

\section{FIJACIÓN DEL CORION PARA MICROSCOPÍA ELECTRÓNICA} DE BARRIDO

El corion de ovas sin fecundar así como de ovas postfecundadas fueron fijados en terreno mediante la utilización de una solución de glutaraldehído al 2,5\% en buffer fos- fato, para luego ser dispuestas en una caja refrigerada y más tarde trasladadas al laboratorio de microscopía del Instituto de Embriología de la Universidad Austral de Chile en Valdivia.

A partir del grupo de ovas que continuó el desarrollo, durante la eclosión de los alevines, se procedió a recolectar el corion de aquellas ovas eclosionadas, las cuales fueron fijadas en las mismas condiciones que las anteriores.

En el caso de ovas que evidenciaron la ocurrencia del fenómeno "corion duro", se procedió primero a disecar el corion de los alevines no eclosionados o parcialmente eclosionados para luego proceder a su fijación utilizando el mismo fijador. El transporte de ambos tipos de corion hasta el laboratorio de Embriología en Valdivia se realizó según el procedimiento más arriba descrito.

\section{MICROSCOPÍA ELECTRÓNICA DE BARRIDO}

Las muestras de corion fueron preparadas para su observación a la Microscopía Electrónica de Barrido (MEB) según el siguiente protocolo. Primero fueron lavadas en buffer fosfato, postfijadas en tetróxido de osmio al $1 \%$ en el mismo buffer, deshidratadas en una batería de alcohol y acetona, seguida de un proceso de secado al punto crítico del $\mathrm{CO}_{2}$ y montadas sobre un portaespecímenes. Finalmente fueron metalizadas por ionización con una capa de oro de $20 \mathrm{~nm}$ de espesor. La observación de las muestras se realizó en un microscopio electrónico de barrido modelo LEO 420.

\section{ANÁLISIS DE IMÁGENES}

Las fotografías de los diferentes tipos de corion obtenidas a la MEB fueron utilizadas para realizar un análisis de imágenes que permitió evaluar cuantitativamente las características del corion de los diferentes tipos de ovas en estudio. En este caso se procedió a realizar mediciones del grosor del corion así como también de las fibras que forman la cara interna del corion. El programa utilizado para este estudio fue SigmaScan pro5 (SPSS Inc.).

\section{RESULTADOS}

El estudio de ovas sin fecundar, de ovas fecundadas, de ovas parcialmente eclosionadas y ovas sin eclosionar de $S$. salar a la MEB reveló que el corion de todas ellas posee similares características estructurales; es decir, que en todos los casos el corion aparece como una envoltura compuesta por dos capas o estratos íntimamente asociados, seguidos de un tercer estrato que presenta una serie de porosidades formando una especie de red y que se dispone próximo a la membrana citoplasmática del ovocito (figura 1).

El estrato externo, que corresponde a la fracción de corion que está en contacto con el medio ambiente, es de apariencia granular y corresponde a una capa fina de aproximadamente $0,2 \mu \mathrm{m}$ de espesor, que se continúa con un segundo estrato (estrato esponjoso), situado inmedia- 
tamente por debajo y que está compuesto por numerosos haces de fibras proteicas ordenadamente entrelazadas. Esta disposición permite la formación de numerosos espacios o poros (aproximadamente 1,15 $\mu \mathrm{m}$ de diámetro) que le otorgan a este segundo estrato la apariencia de una esponja derivando de allí su nombre.

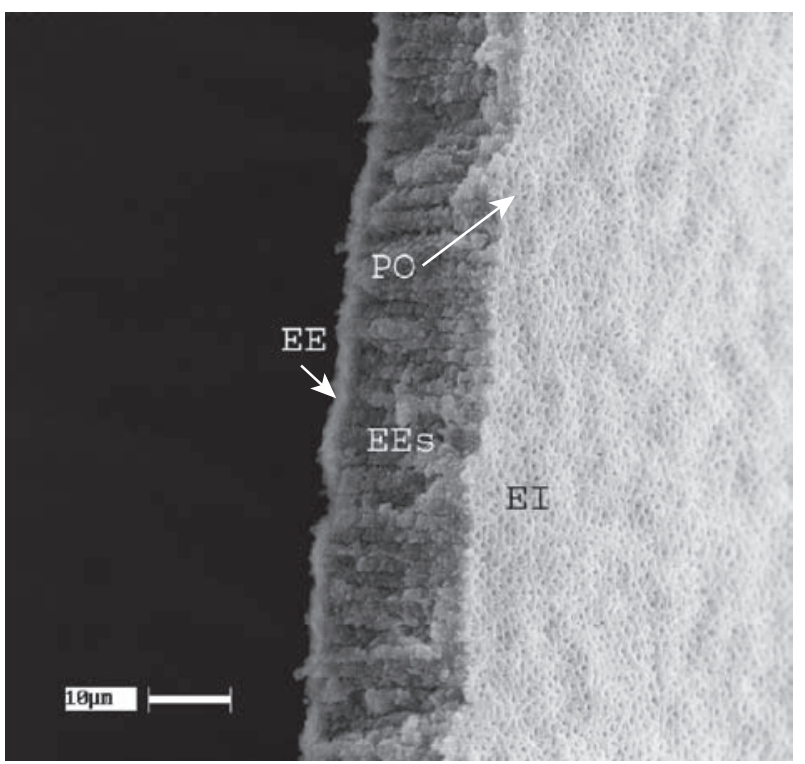

Figura 1. MEB del corion de ovas de Salmo salar recién fertilizadas. (EE = estrato externo; EEs = estrato esponjoso; $\mathrm{EI}=$ estrato interno; $\mathrm{PO}=$ poros que se continúan hacia el estrato esponjoso).

SEM chorion's view of fertilized Salmo salar ova. $(\mathrm{EE}=\mathrm{ex}-$ ternal stratum; EEs = spongy stratum; $\mathrm{EI}=$ inner stratum; $\mathrm{PO}=$ pores connected to the spongy stratum).

El tercer estrato o estrato interno corresponde a la cara del corion que está en contacto directo con la membrana plasmática del ovocito. Este estrato está formado por un entramado muy similar a la estructura de una red que permite la aparición de poros. Los poros tienen su origen en el estrato esponjoso y su prolongación hacia el estrato interno permite el establecimiento de una relación de continuidad entre ambos estratos (figura 2), la que es característica para cada especie de salmónido.

A pesar de estas similitudes en la estructura del corion, se observaron algunas variaciones entre los diferentes tipos de ovas estudiadas. Estas diferencias se producen fundamentalmente al realizar mediciones del grosor del corion y del grosor de las fibras proteicas que constituyen el corion. En el caso del espesor del corion de las ovas no fecundadas este promedio llegó a los 30,5 $\mu \mathrm{m}$, mientras que en el caso de las ovas fecundadas el grosor del corion alcanzó un promedio de 25,5 $\mu \mathrm{m}$ (cuadro 1).

En el caso del grosor de las fibras, las ovas no fecundadas mostraron un grosor $0,16 \mu \mathrm{m}$, mientras que en las ovas fecundadas el grosor fue de 0,29 $\mu \mathrm{m}$ (cuadro 1), no observándose diferencias en la disposición espacial (entramado) de las fibras (figuras 2 y 3 ).

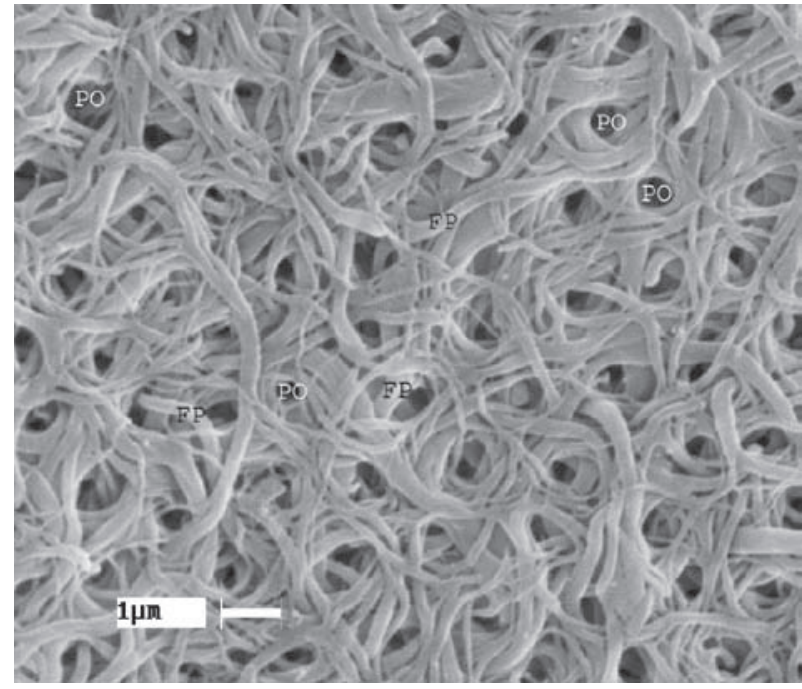

Figura 2. MEB de la cara interna del corion de ovas eclosionadas de Salmo salar (FP = fibras proteicas; $\mathrm{PO}=$ poros que se continúan hacia el estrato esponjoso).

SEM view of chorion's outer stratum from hatched ova of Salmo salar $(\mathrm{FP}=$ protein fibers; $\mathrm{PO}=$ pores connected to the spongy stratum).

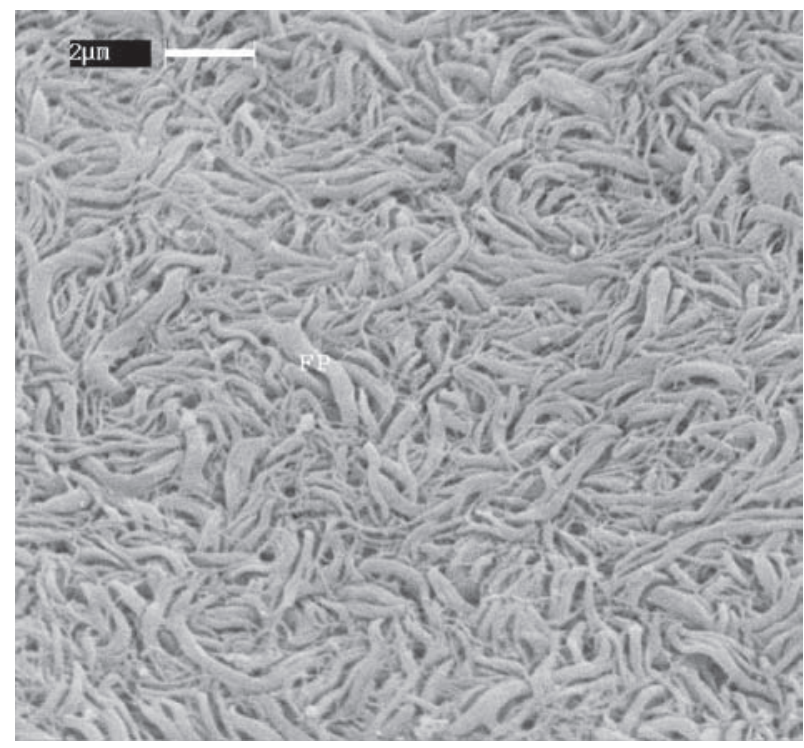

Figura 3. MEB de la cara interna del corion de ovas no eclosionadas de Salmo salar (FP = fibras proteicas). Nótese la ausencia de poros.

SEM inner stratum chorion's view from not hatched ova of Salmo salar (FP = protein fibers). See homogeneous distribution of fibers and absence of pores.

El estudio del corion de ovas eclosionadas, también llamado "corion normal," mostró un grosor del corion promedio de 25,6 $\mu \mathrm{m}$ (cuadro 1), mientras que el grosor del corion de ovas que no permitieron la eclosión de alevines llamadas "corion duro" fue de 25,4 $\mu \mathrm{m}$.

Si bien es cierto que la diferencia en el grosor del corion entre ambos tipos de ovas es mínima, la principal diferencia 
Cuadro 1. Valores promedios en $\mu \mathrm{m}$ obtenidos para parámetros como grosor del corion y fibras del corion para los diferentes tipos de ovas de Salmo salar estudiadas mediante el análisis de imágenes.

Thickness average values $(\mu \mathrm{m})$ obtained for both chorion and chorion fibers from different types of studied ova in Salmo salar.

\begin{tabular}{|c|c|c|c|c|}
\hline \multirow{2}{*}{ Tipo de ovas } & \multicolumn{2}{|c|}{ Grosor del corion } & \multicolumn{2}{|c|}{ Grosor de las fibras } \\
\hline & Promedio $\mu \mathrm{m}$ & Desv. Std. & Promedio $\mu \mathrm{m}$ & Desv. Std. \\
\hline Corion ovas sin fecundar & 30,5 & 7,37 & 0,16 & 0,052 \\
\hline Corion ovas fecundadas & 25,5 & 1,45 & 0,29 & 0,099 \\
\hline Corion normal & 25,6 & 1,08 & 0,18 & 0,058 \\
\hline Corion duro & 25,4 & 2,95 & 0,25 & 0,083 \\
\hline
\end{tabular}

entre ambos tipos de corion viene dada por el grosor de las fibras y por la disposición de éstas en el estrato interno (figuras 2 y 3). En el caso del corion normal, el grosor promedio de las fibras es de $0,18 \mu \mathrm{m}$, mientras que en el caso de "corion duro" las fibras alcanzan un promedio de $0,25 \mu \mathrm{m}$ (cuadro 1 ).

En el caso de las "ovas normales" las fibras que conforman el corion siguen el patrón de ordenamiento observado en las ovas fecundadas y no fecundadas, es decir, mantienen la estructura de una red con poros dispuestos de manera equidistante y que permiten una comunicación entre el estrato interno y el esponjoso.

El estrato interno del corion de ovas que presentan el fenómeno "corion duro" exhibe una disposición regular de las fibras proteicas; sin embargo, esta disposición está completamente alterada ya que no hay formación de la estructura en forma de red característica del corion normal, por lo cual no se aprecia la formación de poros. En este caso las fibras se disponen densamente no permitiendo formación de poros, lo que no hace posible el paso de sustancias hacia el estrato esponjoso (figura 3 ).

\section{DISCUSIÓN}

En general, las ovas de los peces teleósteos presentan una envoltura primaria externa, que le confiere una identidad morfológica y bioquímica a cada especie, y que recibe el nombre de corion (Brivio y col 1991). Este corion es una estructura formada por capas que pueden variar en número y grosor dependiendo de la especie (Cotelli 1998). Las ovas de Salmo salar siguen estos patrones ya descritos exhibiendo tres capas: un estrato externo, un estrato medio o esponjoso y un estrato interno. Del mismo modo, los resultados aquí presentados muestran que el corion de los diferentes estados de desarrollo de las ovas de $S$. salar exhibe de manera regular el mismo número de capas.

Respecto del grosor del corion, los datos nos permiten establecer una variación entre el corion de ovas no fecundadas y ovas fecundadas. La diferencia puede ser explicada debido a que el corion presenta un cierto grado de elasticidad. En el caso de ovas no fertilizadas y no hidratadas, se aprecia más grueso debido a que las primeras no han sido hidratadas y por lo tanto se mantienen como al momento de la ovulación. En el caso de las ovas fecundadas, éstas han permanecido por algunas horas en el agua, por lo que se ha producido ingreso de agua por osmosis al interior de la ova, lo que produce aumento de la presión de turgencia al interior de la ova, la que ejerce presión sobre el corion. Este aumento de la presión interna de la ova conlleva un estiramiento del corion por la resistencia que este último realiza para evitar la ruptura de la ova.

Los valores reportados para el grosor del corion de ovas fecundadas con desarrollo normal y de ovas con corion duro varían en $0,1 \mu \mathrm{m}$. Esto podría estar relacionado con la disposición y grosor de las fibras, lo que podría estar asociado a una menor elasticidad.

Respecto del grosor de las fibras del corion normal, podemos decir que las fibras que forman tanto el corion de ovas no fecundadas y fecundadas no presentan cambios en su grosor, mientras que en el caso del corion duro éstas son definitivamente más gruesas ya que alcanzan los $0,25 \mu \mathrm{m}$. El origen de esta anomalía es de etiología desconocida. Aun cuando se ha encontrado en ovas de reproductores con daño hepático, en reproductores alimentados con dieta de alta energía y reemplazo proteico no existe certeza que pudiesen ser éstas las causas de la anomalía.

La diferencia más notoria entre las ovas con desarrollo normal y aquellas que muestran "corion duro" es que en este último caso el estrato interno no exhibe la característica disposición de red que conecta al ovocito con los poros del estrato esponjoso, por lo tanto no hay continuidad entre el ovocito y el corion.

Estudios publicados acerca del corion han reportado que las principales funciones de éste son permitir la difusión de gases y productos metabólicos de desechos, proporcionar protección mecánica, además de un aislamiento térmico a la ova (Iconomidou y col 2000), facilitando de este modo el desarrollo normal y la posterior eclosión de los alevines. Todas estas funciones se ven facilitadas por la presencia de los poros, situados en el estrato esponjoso, que se encuentran invadidos por microvellosidades que se proyectan desde la membrana plasmática del ovocito y que atraviesan la red de espacios (poros) observados en el estrato interno del corion (Shabanipour y Heidari 2004). 
La ausencia de poros en el estrato interno del corion, por tanto, debiera reducir las funciones normales de éste y con ello afectar la viabilidad del alevín en formación. Por otra parte, las enzimas de eclosión que de manera normal disuelven el estrato interno del corion degradando específicamente ciertas glicoproteínas estructurales que forman parte de la red del estrato interno del corion (Yamagami 1981), facilitando con ello la ruptura del corion (coriólisis), también parecen ser afectadas. La ausencia de poros en el estrato interno no permite o permite sólo de manera parcial la actividad degradativa de las enzimas de eclosión, lo que redunda en la persistencia parcial o total del corion.

Puesto que la síntesis de la coriogenina ocurre en el hígado, es posible pensar que peces con algún tipo de daño hepático podrían producir una forma alterada de alguna de las tres subunidades que constituyen la coriogenina. Esta alteración podría significar que alguna de las subunidades de la coriogenina no se dispone de manera entrelazada, generando con ello un estrato interno del corion carente de poros. De este modo, entonces, el fenómeno denominado "corion duro" podría ser explicado por la ausencia de poros en el estrato interno del corion, con lo que se produciría una restricción de los procesos fisiológicos de las ovas en desarrollo.

\section{RESUMEN}

El "corion duro" es un fenómeno de reciente ocurrencia y se caracteriza porque algunos alevines con ojo no son capaces de degradar el corion que les rodea o lo hacen sólo de manera parcial, produciéndose en ambos casos la muerte del alevín. Este fenómeno ha causado fracasos reproductivos importantes en algunas pisciculturas del sur de Chile, desconociéndose hasta ahora la razón de su ocurrencia. En este estudio se realizaron mediciones del grosor del corion de Salmo salar así como de las fibras que forman parte de éste en ovas fertilizadas, no fertilizadas, con desarrollo normal y ovas que no lograron eclosionar. Los resultados obtenidos indican que las leves variaciones observadas en el grosor del corion entre los diferentes estados de desarrollo de las ovas estudiadas no explican la ocurrencia del "corion duro". Sin embargo, la disposición de las fibras proteicas que forman el estrato interno del corion parece ser la respuesta a este fenómeno. Las ovas que no eclosionan presentan "corion duro" y exhiben un estrato interno carente de poros a diferencia de lo que se observa en las ovas que desarrollan normalmente y que logran la eclosión. Se propone que problemas en la síntesis de alguna de las sub-unidades que forman la coriogenina serían los responsables de la formación de un estrato interno carente de poros, siendo ésta la razón del "corion duro".

\section{REFERENCIAS}

Brivio MF, R Bassi, F Cotelli. 1991. Identification and characterization of the major components of the Oncorhynchus mykiss egg chorion. Mol Reprod Develop 28, 85-93.

Celius T, BT Walther. 1988. Oogenesis in Atlantic salmon (Salmo salar L.) occurs by zonagenesis preceding vitellogenesis in vivo and in vitro. J Endocr 158, 259-266.

Cotelli F. 1998. The fish egg chorion: Cellular and molecular biology. Proceedings of the EMBO-Workshop on reproduction and early development.

Darie CC, ML Biniossek, MA Gawinowics, Y Milgrom, JO Thumfart, L Jovine, ES Litscher, PM Wassaman. 2005. Mass spectrometric evidence that proteolitic processing of Rainbow trout egg vitelline envelope proteins takes place on the egg. J Biol Chem 280, 37585 37598.

Iconomidou VA, DG Chryssikos, V Gionis, MA Pavlidis, SJ Hamodrakas. 2000. Secondary structure of chorion proteins of the teleostean fish Dentex dentex by ATR FT-IR andFT-Raman spectroscopy. J Struct Biol 132, 112-122.

Iuchi I, K Masuda, K Yamagami. 1991. Change in component proteins of the egg envelope (chorion) of rainbow trout during hardening. Develop Growth Differ 33, 86-92.

Masuda K, I Iuchi, K Yamagami. 1992. Some properties of the hardening process in chorions isolated from unfertilized eggs of medaka Oryzias latipes. Develop Growth Differ 34, 545-551.

Shabanipour N, B Heidari. 2004. A histological study of the zona radiate during late oocyte developmental stages in the Caspian sea mugilid, Liza aurata (Risso 1810). Braz J Morph Sci 21, 191-195.

Yamagami K. 1981. Mechanism of hatching in fish: secretion of hatching enzyme and enzymatic choriolysis. Am Zool 21, 459-471. 
